\title{
Repetitive Narrative Techniques Depicting Confrontation in Animated Shorts
}

\author{
Hsien-Yuan Chiu', Ta-Long Lin ${ }^{2}$ \\ ${ }^{1}$ Program of Aesthetics, Media Art and Art History Stream, Department of Fine Art, National Taiwan Normal University, Taiwan \\ ${ }^{2}$ Department of Fine Arts, National Taiwan Normal University, Taiwan \\ Email: Chiou.milkcar@msa.hinet.net, findart@gmail.com
}

How to cite this paper: Chiu, H.-Y., \& Lin, T.-L. (2020). Repetitive Narrative Techniques Depicting Confrontation in Animated Shorts. Art and Design Review, 8, 127-138.

https://doi.org/10.4236/adr.2020.83009

Received: May 9, 2020

Accepted: June 9, 2020

Published: June 12, 2020

Copyright $\odot 2020$ by author(s) and Scientific Research Publishing Inc. This work is licensed under the Creative Commons Attribution International License (CC BY 4.0).

http://creativecommons.org/licenses/by/4.0/

(c) (i) Open Access

\begin{abstract}
In the creation of short animated films, confrontation is a common plot structure. This is because conflict quickly highlights the emphasis of the plot, and allows the audience to focus on the evolution of the event. The repetition technique is an indispensable part of the narrative in confrontation. As there are often core opposing problems in these situations, how the problems are shown from their generation, through evolution to solution must be weighed through the repetition technique to achieve the intensity and change of the opposing event. In other words, while effectively highlighting the focus of the plot, the repetition technique also plays an important role in its evolution and richness. This is also why the narrative technique is often used in short animated films. Given that, the narrative technique is worthy of further discussion and analysis in order to summarize valuable results. This is the core purpose of this study. In this study, the formation conditions and relationship of confrontation plots are clarified through text and case analysis, and further, the operational reasons and functions of the repetition and turning points in the confrontation plots are studied. It is hoped that this study will contribute to the creation and appreciation of animation.
\end{abstract}

\section{Keywords}

Confrontation Narrative, Repetition, Short Animated Films

\section{Research Motives and Questions}

Animation is a highly creative art. Norman Mclaren once said: "Animation is not the art of drawings that move, but the art of drawing the movement". Therefore, the motion performance of animation is fully developed and variable in terms of themes, visual techniques, and narrative layouts. It can imitate reality and imagine the unknown, which is also a characteristic that separates anima- 
tion from other films. In short films, this characteristic is particularly obvious. Due to the time limit of short films, their content cannot include as complex plot structures and symbols as those in long films. Most of them leave a strong impression to viewers through simple structures, and clearly convey the film's message. Therefore, creators often need to use narrative and film rhetoric techniques to skillfully achieve the purpose and effect of the plot. Specifically, the confrontation plot structure and repetition of conflict events have become common methods for the creation of many short films, such as the confrontation between the marmot and the truck in Gopher Broke in 2004 (Fowler, 2004), the confrontation between the birds and sea waves in Piper in 2016 (Barillaro, 2016), and the entanglement between the octopus and the driver in Oktapodi in 2007 (Bocabeille et al., 2007). The reason is that confrontation can create a vivid contrast. Aristotle mentioned three major rhetorical principles in Rhetoric. "Use metaphors, use contrasts, and be vivid" (Aristotle, 2004).

Aristotle (2004). It is from metaphor that we can best get hold of something fresh. When the poet calls "old age a withered stalk", he conveys a new idea, a new fact, to us by means of the general notion of bloom, which is common to both things. The similes of the poets do the same, and therefore, if they are good similes, give an effect of brilliance. The simile, as has been said before, is a metaphor, differing from it only in the way it is put; and just because it is longer it is less attractive. ... So we must aim at these three points: Antithesis, Metaphor, and Actuality. (pp. 156-157)

Vividness is actually the basis of metaphor and contrast. In addition, opposition or contrast can present things from two sides, allowing viewers to focus more on the evolution of events. In the aforementioned animated shorts, confrontation dictates the overall structure of the films. Then, repetition is used to shape the strength of opposition, and to deepen the evolution of the conflicts and plots in order to improve the focus and fun of viewing. In many similar animated short films, confrontation narrative structures and the repetition are inseparable. These seemingly simple narrative techniques can create amazing stories. However, based on the relevant literature, there is a lack of research and discussion about this narrative technique. Therefore, it is worth studying and analyzing, particularly because it is such a common narrative technique. Therefore, in this study, the structural relationship between confrontation plots and repetition is preliminarily discussed through literature and case analysis.

\section{Research Purpose and Limitations}

As mentioned above, the creation of animated short films is often limited by time. How to effectively convey the ideas of a story through pure plot structures and symbols involves not only creativity, but also the application of narrative techniques. In real life, when there is an opposition between a person and their environment, the two engage in confrontation. The method of resolving the conflict becomes a necessary consideration to eliminate the opposi- 
tion. Attempted actions are often necessarily repeated. The course of the confrontation exhibits prominent dramatic properties, and confrontation is often represented and discussed in literary and artistic works. Similarly, in the creation of animated worlds, confrontation plots are indispensable. Especially in animated shorts, such plots run through entire films. Therefore, this study aims to achieve the following three goals:

1) Summarize the formation conditions and types of confrontation plots.

2) Analyze the relationship between repetition and confrontation plots.

3) Analyze the relationship between conflicts and turning points.

In this study, the structure and relationship between confrontation plots and the repetition narrative technique in animated short films are discussed. Two major elements, character and environment, are analyzed. Therefore, film music, sound effects, editing, color and other constituent elements, as well as non-plot art creations, are not included in this study.

\section{Literature Review and Case Analysis}

\subsection{Confrontation Forming under the Subject-Object Relationship}

"Confrontation" represents a struggle or conflict in life where opposite parties hold specific positions. From a psychological perspective, it is motivated by a belief or attitude. Therefore, one party must change to resolve the conflict (Bar-Tal, 2000).

Bar-Tal (2000). From the psychological perspective of conflict analysis, outbreaks of conflicts are dependent on the appearance of particular perceptions, beliefs, attitudes, and motivations, all of which must change for conflict resolution to occur. (p. 352)

Confrontation plays the role of advancing plots in movies, dramas and novels. Meanwhile, the creation of an antagonistic relationship immerses the viewers in the conflict. A good film should depict adversarial relationships, enabling viewers to experience opposing views (Rabiger \& Hurbis-Cherrier, 2003).

Rabiger \& Hurbis-Cherrier (2003). The best cinema is relativistic, that is, it allows us to experience other related but opposing points of view. Used responsibly, this is an immensely civilizing force to offset the conformity imposed by merchandisers striving to convert us into a compliant admass. (p. 205)

Confrontation possesses the nature of conflicting. The two sides in the confrontation realize the results of plots in endless battle, and the process of conflict becomes the focus of the overall confrontation. As the confrontation often builds the conflicting relationship, the focus of the viewer is easily locked on the evolution of a specific event. Such a narrative method that can easily eliminate redundancies and complexity has also become one of the techniques often used in short films to create conflicts. Through the narrative mode of the opposing relationship, the plot can be focalized. A short-term narrative process can concen- 
trate on the enhancement of a certain standpoint. In animated short films, it can clearly explain a concept. According to the relevance of events, focalization can express the standpoints of the narrative, and these positions may not necessarily come from the characters in the plot (Fulton, 2005).

Fulton (2005). Focalisation refers to the viewpoint or perspective from which the narration is told, positioning narrative voices, who may or may not be characters in the story, in relation to events and to each other. (p.

The viewing process is intended to guide viewers to appreciate the confrontational performance but beneath it lies an important message that airs the director's standpoint. This is the aim of focalization produced by repeated confrontation. In the structures of scripts, conflict doesn't necessarily refer to person-to-person confrontation. Instead, it can include conflict between people and the environment, or self conflict (Dancyger \& Rush, 2011). So-called person-to-person confrontation usually develops the narrative through a competitive relationship, and the purpose of the confrontation is to change a certain state. For example, in the 2005 Pixar animated short, One Man Band (Andrews \& Jimenez, 2005), two artists enter into a series of confrontations in order to obtain affirmation and a reward from a little girl. In the Lady and The Reaper (Gracia, 2009), a doctor and Death fight for the spirit of an old lady. These films depict changes in a certain state through competition between their characters. In many animated short films, this confrontation can be enacted by wider varieties of characters, not simply humans. They include anthropomorphic animals, insects, objects and ghosts. Therefore, the performance of the characters and the evolution of plots are more diverse. This is often one of the reasons why animated shorts can create unexpected humor and fun. In addition, person-to-environment confrontation and self-confrontation, as the name suggests, do not happen between multiple characters. In the person-to-person confrontation mentioned above, competition is an indispensable narrative element, and the purpose of competition is to implement change. However, in person-to-environment confrontation and self-confrontation, competition becomes an unnecessary condition. Without the competitive element, the motivation for change determines the difference between person-to-environment confrontation and self-confrontation. For example, the 2016 Pixar animated short, Piper, describes a young bird trying to overcome its fear of sea waves in order to forage on the beach like other big birds. In this film, the young bird confronts the sea, but there is no competitive relationship between the two. The young bird does not try to change the sea in order to overcome its fear. Without competition or change, it is actually a form of self conflict that is realized, and the sea only provides the platform for this confrontation. The ordeal of the young bird is the focus of the entire film. Similarly, in the absence of competition, in the work of Rob Silvestri, Ormie (Silvestri, 2010), a pig tries to get the cookies on the refrigerator, but the refrigerator itself becomes a confrontational obstacle. There 
is motivation to change a certain state during the repeated attempts of the pig. This motivation for change is different from the confrontation in Piper, and is a true person-to-environment confrontation. The above case shows that the tension of conflict is constantly changing under the premise of desire. Therefore, without the motivation for change, it is impossible to obtain a more intense narrative in the process of conflict. Table 1 summarizes the types of confrontation and case analysis of Dancyger and Rush from three dimensions, including competitive conditions, motivation for change, and viewing focus, and concludes with the confrontation types in the cases.

From the above table, we can preliminarily understand that in many animated short films, the key formation conditions for confrontation involve competition and motivation for change. These two conditions determine the viewing focus and confrontation type in the film (Table 2). In brief, the focus of the confrontation between the characters is the competition. However, when the competition does not exist in the narrative, but the characters strive to challenge or overcome, the situation orients toward overcoming the state of the characters themselves (or mentality) and changing the objective environment, which often occurs when the confrontation subject is external.

Table 1. Confrontation types in cases (Compiled by this study).

\begin{tabular}{|c|c|c|c|}
\hline \multicolumn{4}{|c|}{ Person-to-person confrontation } \\
\hline Case & Competition conditions & Motivation for change & Viewing focus \\
\hline One Man Band & Two street artists & $\begin{array}{l}\text { Create attraction and } \\
\text { change the decision of } \\
\text { the little girl. }\end{array}$ & $\begin{array}{l}\text { How the two artists } \\
\text { compete with each other } \\
\text { by art }\end{array}$ \\
\hline $\begin{array}{l}\text { The Lady and the } \\
\text { Reaper }\end{array}$ & Doctor and death & $\begin{array}{l}\text { Control the spirit of the } \\
\text { old lady. }\end{array}$ & $\begin{array}{l}\text { How both parties fight } \\
\text { for the spirit of the old } \\
\text { lady }\end{array}$ \\
\hline \multicolumn{4}{|c|}{ Person-to-environment confrontation } \\
\hline Case & Competition conditions & Motivation for change & Viewing focus \\
\hline Ormie & None & $\begin{array}{l}\text { Overcome the obstacles } \\
\text { with tools }\end{array}$ & How to get the cookies \\
\hline \multicolumn{4}{|l|}{ Self-confrontation } \\
\hline Case & Competition conditions & Motivation for change & Viewing focus \\
\hline Piper & None & None & $\begin{array}{l}\text { How the young bird } \\
\text { overcomes its fears }\end{array}$ \\
\hline
\end{tabular}

Table 2. Differences in conditions of different confrontation types (Compiled by this study).

\begin{tabular}{llll}
\hline Confrontation types & Competition conditions & Motivation for change & Viewing focus \\
\hline Person-to-person confrontation & $X$ & $\bigcirc$ & Competition \\
Person-to-environment & $X$ & $X$ & Overcome \\
confrontation & $X$ & outside \\
Self-confrontation & & Overcome inside \\
\hline
\end{tabular}


Many animations or movies contain elements of confrontation elements, and even the universal plots. In Substance, Structure, Style and the Principles of Screenwriting, Robert McKee mentions that the principles of conflicts include contradictions, opposition, and negation of negation. Contradictory values form a binary relationship based on relativity, just as the opposite of "good" is "evil". Contrary values have a critical meaning. Finally, negation of negation is a comprehensively negative situation in which things have gone to the worst. However, what role do confrontations and conflicts play in drama? Indick (2011) mentioned that the character's confrontational behavior is to show its deep desires. Confrontation can effectively solve problems through the practice of behaviors, and the premise for such behaviors is the desire to solve the problem. This desire is also based on necessity and rationality in short story plots. In other words, when confrontation plots produce conflict or opposition, all resulting actions are based on desires.

\subsection{Relationship between Conflicts and Repetition}

As mentioned above, in animated shorts, the narrative of confrontation plots is often laid out with repetition. This technique can intensify the conflict in the narrative. Therefore, techniques used to display confrontation plots through repetition are the key focus of this section. In view of this, the role of repetition in rhetoric is clarified, and then the significance of repetition and conflict in animated shorts is discussed.

In the field of literary rhetoric, the philosopher Aristotle explained the importance of rhythm in repetitive speech, allowing repetitive phenomena to appear in the minds of readers, and also generating expectations (Landa, 2004).

García Landa (2004). Aristotle underlines the importance of rhythm in diction. He defines rhythm as the repetitition of similar elements, which works through the expectation arised in the hearer: the hearer knows that such and such elements will recur. (p. 33)

Samuel Taylor Coleridge suggested that the repetition of poetry is an expression form for immersion in the process. He claimed that the fun of poetry lies in the perception of repetitive reading, not just reading in words (Coleridge, 1971).

Coleridge (1971). Not the poem which we have read, but that to which we return, with the greatest pleasure, possesses the genuine power, and claims the name of essential poetry. (p. 14)

However, this regular pattern is a means of aesthetic expression. The repetitive singing in poetry deepens the relationship between the words and produces new emotions every time. The repetitive pattern allows semantic with aesthetic expression and produces rhythm and links between the words. It even produces the parallelism effect in the process (Ribeiro, 2007).

Ribeiro (2007). These patterns serve various aesthetic and semantic func- 
tions: they create rhythm (meter, rhyme), emphases and connections (rhyme, anaphora, assonance), and invite comparisons and contrasts (parallelism, stanzas, alliteration). (p. 191)

Therefore, the key point of repetition in rhetoric lies in a process of repetition beyond the literal meaning. It is used to achieve an expected psychological and immersive effect, that resonates with readers through rhythm and regularity. In addition, repetition can produce perception other than the phenomena. Therefore, when repetitive rhetoric is used in film creation, its purpose is also to achieve perception beyond the films. For example, in the 2005 Pixar animated short film, One Man Band, two street artists want to win a gold coin from the little girl. As the conflicting events keep repeating, the competition becomes the narrative axis of the entire film, letting people focus on how these two street artists use all their means to get money from the little girl. Humor and fun have replaced the conflicting process and the film. In addition, this repetitive narrative technique often shows different practical behaviors with the same conflicting elements in order to achieve the same purpose. For example, in One Man Band, the conflict between the two artists is repeated, but the competitive behaviors are indeed different each time. From another Pixar animated short film, Geri's Game, throughout the confrontation between an old man and his shadow, the repetition of interesting games carries the purpose of winning the game. In other words, the repetition process must contain variation and difference. Through repetition, the conflicting events are skillfully stacked in different aspects, keeping the viewers' focus locked on the events, and showing them varied dramatic performances.

In the previous section, we discussed that the confrontation plots show examples of conflict, and confrontation is a way to quickly focus on the conflicting events in the plots. Moreover, repetition plays an important role in developing these conflicting plots. To sum up, repetition is a narrative technique that intensifies the plots and deepens the emotions they elicit. Through repetition, viewers can clearly understand the intensity and meaning of the conflicts. The confrontation is just the key to open this series of conflicts. In addition, it was found during the research process that the repetition technique in animation often cooperates with the principles of gradation, rhythm, and cycle to achieve the best narrative effect.

\subsection{Turning Points in Conflicts}

The main purpose of turning points in plots is to change the inertia of the narrative, release the cumulative energy of the plot, and turn the plot to another narrative track. However, no matter the narrative tracks to which the turning points turn the plots, the purpose is to make the plots nearly perfect. In Substance, Structure, Style and the Principles of Screenwriting, Robert McKee writes: a "trigger event" needs to subvert the balance of the characters in the narrative. An event will inevitably have an impact when entering the character's worldview, 
and the turning points should cause fluctuations in this worldview and the situation. The other principal purpose is to heighten emotions. The narrative will reach its climax over time, and finally, the emotions of the plots are eased through the resolution (Block, 2013).

Block (2013). The intensity begins to build as the story moves into the conflict (CO). The intensity of the conflict continues to increase until the cli$\max (\mathrm{CX})$, which is the most intense part of the story conflict. In the resolution $(\mathrm{R})$, the story intensity diminishes and the story ends. ... The story conflict increases in intensity until it reaches the climax and then quickly decreases in intensity during the resolution. (p. 226)

The principle of narrative is to resonate with viewers. Therefore, the focus of the previous plots is to obtain the viewers' "recognition". When the emotion of recognition accumulates to a certain extent, turning points allow the viewers to adhere to the changing plot points due to their subversion of expectations.

In the 2007 animated work Oktapodi, produced by Julien Bocabeille et al., an octopus engages in a series of conflicts with a truck driver to save his girlfriend. Eventually, after the octopus squirted ink, the driver fell into the sea, which ended the confrontation. The key turning point of the plot lies in the competition between the characters, allowing the strong side to defeat the weak side. In this case, when the driver takes the octopus's girlfriend from the aquarium, the confrontation relationship is formed through repeated competition between the two sides (viewing focus), the plot turns when octopus spits ink. In 2004, in $\mathrm{Go}$ pher Broke, a mole discovers that a moving truck is fully loaded with fruits and vegetables, which forms a confrontation between the two. The narrative consists of the mole's repeated attempts to get the food. The turning point is when the enraged mole destroys a street sign, exposing some iron nails. It is a continuous effect of plot coherence. The term coherence is used in epistemology to express the relationship between events (Repp, 2017).

Repp (2017). Epistemologists typically use the term coherence to denote a certain type of relation among the propositional contents of a person's beliefs. (p. 60)

This condition and relationship from confrontation to repetition to turning point can be found in all the cases mentioned in this study. The formation conditions of turning points depend on repetitive elements. Table 3 summarizes the formation conditions for turning points.

The above table verifies that the preconditions of the turning points in each case are closely related to repetitive elements. Without the repetitive elements, it is impossible to find the turning points. For example, in One Man Band, if the two artists did not compete for the coin in the hands of the little girl, the gold coin would not fall in the ditch. In Gopher Broke, if the mole did not become frustrated, he would not have broken the street sign or expose the nails. In $\mathrm{Fa}$ ther and Daughter (Wit, 2000), if the lake water did not become land, the wom- 
an would not see her father again. In addition, the plot development of the turning points should be reasonable. The turning points of the plots, such as the octopus spitting ink in Oktapodi, the street sign in Gopher Broke broken by the mole, or the transformation of the lake to land Father and Daughter, must be logically designed, rather than whimsical or sudden switches so as to guide the viewers to different plot tracks. In addition, turning points can also be regarded as a qualitative change, which is based on quantitative change. A qualitative change is a sudden change or leap from one property to another. In other words, repetition is like a quantitative change, and turning points are the qualitative change produced in the process. Based on the continuous operation of the quantitative change, the qualitative change keeps transforming the plot, and finally, ends the inertia of the quantitative change.

Table 3. Formation conditions for turning points (Compiled by this study).

\begin{tabular}{|c|c|c|c|}
\hline Case & Repetitive elements & Turning points & Results \\
\hline Oktapodi & $\begin{array}{l}\text { Truck, driver, } \\
\text { octopus, street }\end{array}$ & $\begin{array}{l}\text { The octopus spits ink, blocking } \\
\text { the driver's sight. }\end{array}$ & $\begin{array}{l}\text { The octopus is thrown away by } \\
\text { the car, and the driver falls into } \\
\text { the water with the truck. }\end{array}$ \\
\hline $\begin{array}{l}\text { Gopher } \\
\text { Broke }\end{array}$ & $\begin{array}{l}\text { Mole, farmland, } \\
\text { road, street sign, } \\
\text { moving truck }\end{array}$ & $\begin{array}{l}\text { Because the mole cannot get the } \\
\text { food on the truck, he throws the } \\
\text { street sign on the road, exposing } \\
\text { the nails. }\end{array}$ & $\begin{array}{l}\text { The tire of the moving truck is } \\
\text { punctured by the iron nails, and } \\
\text { the cow on the car falls out and } \\
\text { squashes the mole. }\end{array}$ \\
\hline $\begin{array}{l}\text { One Man } \\
\text { Band }\end{array}$ & $\begin{array}{l}\text { Two artists, musical } \\
\text { instruments, little } \\
\text { girl, gold coins, tin } \\
\text { can, square }\end{array}$ & $\begin{array}{l}\text { Due to the competition between } \\
\text { the two artists, the gold coins of } \\
\text { the little girl accidentally fall into a } \\
\text { ditch. }\end{array}$ & $\begin{array}{l}\text { The little girl gets angry, borrows } \\
\text { a musical instrument and a tin } \\
\text { can, becomes a street artist } \\
\text { herself, and earns a lot of gold } \\
\text { coins. }\end{array}$ \\
\hline $\begin{array}{l}\text { The Lady } \\
\text { and the } \\
\text { Reaper }\end{array}$ & $\begin{array}{l}\text { Doctor, nurse, } \\
\text { emergency room, } \\
\text { old lady, Death, } \\
\text { spiritual space }\end{array}$ & $\begin{array}{l}\text { Conflict between Death and the } \\
\text { doctors and nurses stops Death } \\
\text { capturing the spirit of the old lady. }\end{array}$ & $\begin{array}{l}\text { The lady is rescued, contrary to } \\
\text { her expectations. She is angry and } \\
\text { commits suicide. Death is angry } \\
\text { at receiving an instruction to take } \\
\text { the lady's spirit. }\end{array}$ \\
\hline Ormie & $\begin{array}{l}\text { Pig, refrigerator, } \\
\text { cookies in a glass } \\
\text { jar, tools }\end{array}$ & $\begin{array}{l}\text { After countless failures, the pig } \\
\text { inadvertently leans back, causing } \\
\text { the cookies in the glass jar on the } \\
\text { refrigerator to fall. }\end{array}$ & $\begin{array}{l}\text { When the pig is happily enjoying } \\
\text { the cookies, the glass jar with the } \\
\text { cookies drops and covers the pig's } \\
\text { head. }\end{array}$ \\
\hline Piper & $\begin{array}{l}\text { Young bird, beach, } \\
\text { flock of birds, waves }\end{array}$ & $\begin{array}{l}\text { The young bird tries to overcome } \\
\text { its fear of the sea waves, and } \\
\text { accidentally discovers how a } \\
\text { hermit crab avoids the waves, and } \\
\text { learns how to overcome its fear. }\end{array}$ & $\begin{array}{l}\text { The young bird discovers a } \\
\text { beautiful scene under the sea, } \\
\text { which changes his view of the sea } \\
\text { waves. }\end{array}$ \\
\hline $\begin{array}{l}\text { Father } \\
\text { and } \\
\text { Daughter }\end{array}$ & $\begin{array}{l}\text { Girl, bicycle, } \\
\text { riverbank, lake }\end{array}$ & $\begin{array}{l}\text { The girl visits the riverbank } \\
\text { countless times, and becomes an } \\
\text { old woman, and the lake } \\
\text { transforms into a meadow. }\end{array}$ & $\begin{array}{l}\text { Eventually, the girl walks down } \\
\text { the riverbank and walks to the } \\
\text { middle of the lake as if to see her } \\
\text { father again. }\end{array}$ \\
\hline $\begin{array}{l}\text { Geri's } \\
\text { Game }\end{array}$ & $\begin{array}{l}\text { Old man, shadow, } \\
\text { park, tables and } \\
\text { chairs, chessboard } \\
\text { and pieces }\end{array}$ & $\begin{array}{l}\text { The old man cheats the shadow } \\
\text { and reverses the unfavorable chess } \\
\text { situation. }\end{array}$ & $\begin{array}{l}\text { Win the dentures, and feel } \\
\text { complacent. }\end{array}$ \\
\hline
\end{tabular}




\section{Conclusion and Suggestions}

The creation of animated short films is inherently highly expressive, and the content of the plots covers a wide range of topics. Therefore, every creator must face the difficulty of displaying rich plots through simple themes within a limited time. In this study, the subject-object confrontation form, the relationship between conflicts and repetition, and the turning points in conflicts are investigated through the analysis of the relationship between the confrontation plots and repetition. The key points and conclusions are briefly summarized as follows:

1) Confrontation plots are often simplified, which can focus the viewers quickly on the conflicts at hand. Conflicts generally focus on competition and the variable conditions of motivation for change. In different combinations of conditions, confrontation plots can be divided into person-to-person confrontation, person-to-environment confrontation and self-confrontation. The foundation of the person-to-person confrontation lies in competition and change, while the focus of the conflict is narration around the two conditions. The person-to-environment confrontation lies in change while the focus of the conflict is on how the characters change the external state through their behavior. Finally, in self-confrontation without competition and changing conditions, the focus of the conflict is on how the characters confront and overcome their problems.

2) Repetition is a rhetorical device that deepens the viewers' expectations and immersive process, and the conflicts produced by confrontation must extend the plot by repetition. Applying plot stacking to deepen narrative intensity, and allowing the viewers to feel the change in the conflict through different viewpoints through repetition are an indispensable technique in the narrative of the confrontation plots in animated shorts. In addition, repetitive narrative technique is often targeted at the elements of viewers' focus in the plots, and the repetition must adhere to the principle of seeking difference from similarity, in order to maintain the viewers' understanding of the plot, which is also the most elusive but critical point in the repetition technique.

3) When conflicting plots keep repeating, turning points are an important element to overcome narrative inertia, resolve the conflict and turn to the ending. Especially in animated shorts, these turning points are the key to each film's success. Therefore, it is helpful to understand the preconditions and principles of the turning points in order to improve creativity. This research reveals that the preconditions and principles of turning points consist of the following two aspects:

a) The preconditions of turning points come from repetitive conflicting elements. In other words, the method by which conflicting plots produce turning points is a qualitative change between the conflicting elements, which provides an outlet for releasing pressure.

b) The turning points must be based on the causal relationship of the conflict to produce a reasonable qualitative change so that readers recognize the plot is. 
Whimsical turning points cannot draw the resonance of the readers, but cause the plots to fail.

As mentioned above, the preliminary composition logic and relationship between confrontation, repetition, and turning points can be derived, which provides a starting point for the study of animation or its creators. However, in the analysis process, how conflicting elements achieve the best narrative effect through repetition, and produce qualitative changes to become turning points cannot be explained purely through literature review and case analysis because the above issues involve changes in plot elements, and different variants will lead to different developments and results in the plot. For example, in Ormie, the plot that makes everyone laugh is produced by repeating those elements. How the turning points of transforming the lake into land are considered in the father and daughter, and how two consecutive turning points occur in the plot of The Lady and the Reaper and the Oktapodi can be explained by the delicate and complex plot elements, which is a way of creative thinking, rather than a formulated calculation. Therefore, for such questions, it is recommended that in addition to further case analysis, there must be verification through the experimental process to find a better answer. It is hoped that this preliminary discussion will provide a reference for future beginners in the creation animation, and contribute to animation teaching.

\section{Conflicts of Interest}

The authors declare no conflicts of interest regarding the publication of this paper.

\section{References}

Andrews, M., \& Jimenez, A. (2005). One Man Band.

Aristotle (2004). Rhetoric (Roberts, W.R., Trans., Reprint ed.). North Chelmsford, MA: Courier Corporation.

Barillaro, A. (2016). Piper.

Bar-Tal, D. (2000). From Intractable Conflict through Conflict Resolution to Reconciliation: Psychological Analysis. Political Psychology, 21, 351-365.

https://doi.org/10.1111/0162-895X.00192

Block, B. (2013). The Visual Story: Creating the Visual Structure of Film, TV and Digital Media. Abingdon-on-Thames: Routledge. https://doi.org/10.4324/9780080551692

Bocabeille, J., Chanioux, F.-X., Delabarre, O., Marchand, T., Marmier, Q., \& Mokhberi, E. (2007). Oktapodi.

Coleridge, S. T. (1971). Biographia Literaria. United Kingdom: Scolar Press.

Dancyger, K., \& Rush, J. (2011). Alternative Scriptwriting: Successfully Breaking the Rules (Yi, C.Y., et al., trans.). Taipei: Yuan-Liou Publishing. https://doi.org/10.4324/9780080475226

Fowler, J. (2004). Gopher Broke.

Fulton, H. (2005). Film Narrative and Visual Cohesion. In H. Fulton, et al. (Eds.), Narrative and Media (pp. 108-122). Cambridge: Cambridge UP.

https://doi.org/10.1017/CBO9780511811760.009 
García Landa, J. A. (2004). Aristotle’s Poetics.

Gracia, J. R. (2009). The Lady and the Reaper.

Indick, W. (2011). Psychology for Screenwriters: Building Conflict in Your Script (Jing, Y.C., trans.). Taipei: Wu Nan Books.

Rabiger, M., \& Hurbis-Cherrier, M. (2003). Directing. Film Techniques and Aesthetics. Abingdon-on-Thames: Taylor \& Francis.

Repp, C. (2017). Coherence, Literary and Epistemic. The Journal of Aesthetics and Art Criticism, 75, 59-71. https://doi.org/10.1111/jaac.12342

Ribeiro, A. C. (2007). Intending to Repeat: A Definition of Poetry. The Journal of Aesthetics and Art Criticism, 65, 189-201. https://doi.org/10.1111/j.1540-594X.2007.00249.x

Wit, M. D. D. (2000). Father and Daughter. 